\title{
Lepidagathis alopecuroides methanol extract as corrosion inhibitor for mild steel in $\mathrm{HCl}$
}

\author{
Gloria I. NDUKWE, ${ }^{1}$ Habibat F. CHAHUL ${ }^{*}, 2$ and Godwin OODO ${ }^{2}$ \\ ${ }^{1}$ Department of Chemistry, Rivers State University, Nkpolu-Oroworukwo, Port Harcourt, Rivers State, Nigeria \\ ${ }^{2}$ Department of Chemistry, Federal University of Agriculture, Makurdi, Nigeria
}

\begin{abstract}
We report on the preliminary phytochemical screening of the methanolic extract of the aerial parts of Lepidagathis alopecuroides and its evaluation as a potential corrosion inhibitor for mild steel in aerated $1.0 \mathrm{M} \mathrm{HCl}$ by weight loss and linear polarization measurements. Weight loss measurements were conducted at 303, 313, 323 and 333 $\mathrm{K}$. The results showed that $L$. alopecuroides inhibited the corrosion of mild steel in the acid solution with inhibition efficiency increasing with increase in the concentrations of the plant extract but decreased with increase in temperature. Linear polarization plots showed the plant extract to inhibit both the dissolution of the steel at the anode and the hydrogen evolution reaction (HER) at the cathode making it a mixed inhibitor. Temkin adsorption isotherms best modeled the adsorption of $L$. alopecuroides extract on the steel surface. From the values of the evaluated kinetic activation parameters in the study, the mechanism of physisorption is proposed for the adsorption of the plant extract on the steel surface.
\end{abstract}

Keywords: mild steel; corrosion inhibitor; linear polarization; activation energy; adsorption isotherm.

\section{Introduction}

Steel is a significant form of alloy because of its low cost and extensive engineering applications. Corrosion of steel structures leads to the malfunction and eventual breakdown of components and systems both in the processing and manufacturing industries, and diminishing life times of many components $[1,2]$. The application of corrosion inhibitor formulations on steel structures is an effective and practical approach in mitigating the corrosion of steel parts exposed to different kinds of electrolytes $[1,2]$. These formulations usually contain chemical compounds that possess hetero-atoms like oxygen, nitrogen and sulfur in aromatic or conjugated systems which serve as adsorption centers to the steel surface [3-7].

Many inorganic and organic compounds are reportedly in use as corrosion inhibitors against the corrosion of steel in aqueous media [8-10]. Most of these compounds are however toxic and are sources of environmental and health concerns. Hence, there is the need to search for environmentally friendly substitutes [3-7].

Plant materials are promising green corrosion inhibitors for steel as revealed by several studies [1115]. Plant materials are not only organic but eco-friendly and pose less health concerns in respect of their toxic effects to man and animals compared to inorganic corrosion inhibitors like the salts of vanadium and chromium, and some toxic synthetic organic compounds [16]. Plant materials are rich sources of heterocyclic compounds like tannins, saponins, flavonoids and alkaloids $[11,12]$ which also contain heteroatoms.

The current study presents the preliminary phytochemical screening of the methanol extract of the aerial parts of L. alopecuroides plant and investigations of its potential as a corrosion inhibitor for mild steel in 1.0 $\mathrm{M} \mathrm{HCl}$.

\section{Experimental}

\subsection{Materials}

Mild steel strips were purchased from the steel market in Markurdi Nigeria. The chemicals of high purity $\left(\mathrm{C}_{2} \mathrm{H}_{5} \mathrm{OH}, \mathrm{CH}_{3} \mathrm{COCH}_{3}, \mathrm{~Pb}\left(\mathrm{CH}_{3} \mathrm{COO}\right)_{2}, \mathrm{NaOH}, \mathrm{CHCl}_{3}\right.$, $\mathrm{CH}_{3} \mathrm{COOCOCH}_{3}, \mathrm{H}_{2} \mathrm{SO}_{4}, \mathrm{FeCl}_{3}, \mathrm{CH}_{3} \mathrm{COOH}, \mathrm{NH}_{3}, \mathrm{HCl}$, Wagner and Mayers' reagents) were obtained from Zayo-Sigma (ZSA) Chemicals Ltd - Jos. Nigeria and used without further purification.

\subsection{Preparation of mild steel coupons}

Mild steel strips were cut into the dimension of $30 \times 20$ $\mathrm{x} 1.5 \mathrm{~mm}$ with holes of about $2.0 \mathrm{~mm}$ radius drilled into them. They were then polished with emery clothes, washed in ethanol, degreased in acetone, air-dried and stored in a desiccator prior to immersion in the test solutions for the experiments.

\subsection{Preparation of plant extracts}

Fresh aerial parts of $L$. alopecuroides were harvested from Emouha, Rivers state in Nigeria. L. alopecuroides plant materials were air dried and pulverized after which $300 \mathrm{~g}$ of the dried plant materials in $1 \mathrm{~L}$ of methanol were subjected to microwave assisted extraction [4, 17]. Plant extract was concentrated at $40{ }^{\circ} \mathrm{C}$ using a rotary evaporator (Heidolph Laborata 4002) [17] to obtain $12.72 \mathrm{~g}$ of the dark green extract having colloidal texture.

\footnotetext{
*Corresponding author. E-mail addresses: momohbat2007@gmail.com; chahul.hf@uam.edu.ng (H.F. Chahul)
} 


\subsection{Phytochemical screening}

Preliminary phytochemical investigations were carried out using standard procedures as described by Ndukwe et al. [17].

Test for alkaloids. About $0.5 \mathrm{~g}$ of L. alopecuroides extract was stirred into $3 \mathrm{~mL}$ of $1 \%$ aqueous $\mathrm{HCl}$ on a steam bath and the mixture was filtered. $1 \mathrm{~mL}$ each of the filtrate was treated with 3 drops of Wagner's and Mayer's reagents, respectively [17]. Precipitation was observed for both reagents.

Test for flavonoids. (i) Lead acetate test. A $100 \mathrm{mg}$ of L. alopecuroides extract was dissolved in $5 \mathrm{~mL}$ of distilled water, and $\mathrm{Pb}\left(\mathrm{CH}_{3} \mathrm{COO}\right)_{2}$ solution was added to the solution [17]. Neither color change nor precipitation was observed. (ii) Sodium hydroxide test. $5 \mathrm{~mL}$ of $20 \%$ of $\mathrm{NaOH}$ was added to equal volume of dissolved $L$. alopecuroides extract (100 mg of the extract in $5 \mathrm{~mL}$ of distilled water) [17]. There was no observable change.

Test for steroids (Salkowski's test). L. alopecuroides extract $(100 \mathrm{mg}$ ) was dissolved in $2 \mathrm{~mL}$ of chloroform. $\mathrm{H}_{2} \mathrm{SO}_{4}$ was carefully added to form a lower layer [17]. A reddish-brown color at the interface was observed.

Test for terpenes (Lieberman's test). About $0.5 \mathrm{~g}$ of L. alopecuroides extract was dissolved in $5 \mathrm{~mL}$ of chloroform, $1 \mathrm{~mL}$ of acetic anhydride was added, and then $1 \mathrm{~mL}$ of concentrated sulfuric acid was poured down the wall of the test tube to form a layer underneath [17]. There was formation of a reddish violet color at the junction of the two liquids and a green color in the chloroform layer.

Test for glycosides (Keller Killian test). $L$. alopecuroides extract $(100 \mathrm{mg}$ ) was dissolved in $1 \mathrm{~mL}$ of glacial acetic acid containing 1 drop of $\mathrm{FeCl}_{3}$ solution. This was then under laid with $1 \mathrm{~mL}$ concentrated $\mathrm{H}_{2} \mathrm{SO}_{4}$ [17]. A brown ring was observed at the interface.

Test for tannins. About $0.5 \mathrm{~g}$ of L. alopecuroides extract was stirred into $1 \mathrm{~mL}$ of distilled water, filtered and $\mathrm{FeCl}_{3}$ solution added to the filtrate [17]. There was no observable reaction. Therefore, no blue-green precipitate was observed.

Test for saponins (Frothing test). A $0.5 \mathrm{~g}$ of $L$. alopecuroides extract was shaken with distilled water in a test tube. This was warmed on a water bath [17]. There was frothing or foaming which persisted after warming.

Test for anthraquinones (Borntrager's test). About $0.5 \mathrm{~g}$ of $L$. alopecuroides extract was taken into a dry test tube and $5 \mathrm{~mL}$ of chloroform was added and shaken for $5 \mathrm{~min}$. The solution was filtered, and the filtrate shaken with an equal volume of $25 \% \mathrm{NH}_{3}$ solution [17]. There was no change observed, thus, no observable bright pink color in the upper aqueous layer.

\subsection{Preparation of L. alopecuroides solution as corrosion inhibitor}

Test solutions for gravimetric measurements were prepared as reported in earlier studies by Chahul et al. $[6,18,19]$. Various concentrations of $0.2 \mathrm{~g} / \mathrm{L}, 0.4 \mathrm{~g} / \mathrm{L}$, $0.6 \mathrm{~g} / \mathrm{L}, 0.8 \mathrm{~g} / \mathrm{L}$, and $1.0 \mathrm{~g} / \mathrm{L}$ of $L$. alopecuroides extract were prepared in $100 \mathrm{~mL}$ of $1.0 \mathrm{M} \mathrm{HCl}$ solution and used for the experiments. A blank was prepared without the plant extract to serve as a control.

\subsection{Weight loss measurements}

Weight loss measurements were done as described elsewhere $[12,19,20]$. Already cleaned and preweighed mild steel (MS) coupons were immersed in duplicates in $100 \mathrm{~mL}$ of $1.0 \mathrm{M}$ solution of $\mathrm{HCl}$ in the absence and presence of different concentrations of $L$. alopecuroides extract and left for the period of 3, 6, 9, $12,24,48,72,96$ and $120 \mathrm{~h}$. The coupons were removed from the test solutions each time, washed in water, cleaned with ethanol, dried with acetone, and reweighed. The effect of temperature on the corrosion of mild steel in the acid medium in the absence and presence of various concentrations of $L$. alopecuroides was investigated in a thermostated water bath at 303, 313,323 and $333 \mathrm{~K}$ at $2 \mathrm{~h}$ immersion period.

The weight loss was taken to be the disparity between the initial and final weights of the mild steel coupons at a given time.

The difference in weights $\left(\mathrm{g} \cdot \mathrm{h}^{-1}\right)$ was calculated using Equation 1 [12, 20]:

$$
\Delta w=w_{2}-w_{1}
$$

where $\Delta w=w_{2}-w_{1}$ is the weight loss of metal after a given time. Inhibition efficiency (\%IE) and surface coverage $(\theta)$ were calculated using:

$$
\begin{aligned}
& I E_{\text {exp }}=\left(1-\frac{W_{\text {inh }}}{W_{\text {blank }}}\right) \times 100 \\
& \theta=1-\frac{W_{\text {inh }}}{W_{\text {blank }}}
\end{aligned}
$$

where $w_{\text {inh }}$ and $w_{\text {blank }}$ are the weight loss $(\mathrm{g})$ of the mild steel in the presence and absence of the inhibitor respectively $[12,20]$.

\subsection{Linear polarisation analysis}

A Metrohm Autolab AUT50280 potentiostat with a three-electrode design that has an MS working electrode, Pt auxiliary electrode and saturated calomel electrode (SCE) as reference electrode was employed to perform linear polarisation analysis. Mild steel coupons of $1 \times 1 \mathrm{~cm}^{2}$ dimensions, sealed with epoxy resin in such a way that only $1 \mathrm{~cm}^{2}$ surface area left uncovered, were employed for the experiment. Linear polarization was conducted at room temperature in the potential range of -1500 to $1500 \mathrm{mV}$ and a scan rate of $0.012 \mathrm{v} / \mathrm{s}$.

The anodic and cathodic Tafel curves were extrapolated to corrosion potential to obtain the corrosion current densities $\left(I_{\text {corr }}\right)$ [14]. Inhibition efficiency was calculated using Equation 4 [5, 20]:

$$
I E(\%)=\frac{I_{\operatorname{corr}(\text { blank })}-I_{\operatorname{corr}(\text { inh })}}{I_{\operatorname{corr}(\text { blank })}} \times 100
$$

where $I_{\text {corr (blank) }}$ is the corrosion current density of the steel coupon in the acid solution in the absence of $L$. alopecuroides and $I_{\operatorname{corr}(i n h)}$ is the corrosion current density of the steel coupon in the presence of $L$. alopecuroides [5, 20].

\section{Results and discussion}

\subsection{Phytochemical screening}

Results of the preliminary phytochemical screening of methanol extract of the aerial parts of $L$. alopecuroides 
show the presence of alkaloids, saponins, steroids, terpenes and glycosides but flavonoids, tannins and anthraquinones were absent.

\subsection{Weight loss studies}

The effect of immersion time on weight loss of the steel coupons was investigated as illustrated in Figure 1. The plots in Figure 1 depict a remarkable steady decrease in the weight loss of the metal coupon as L. alopecuroides concentration increased. From this result, it can be inferred that $L$. alopecuroides extract retarded the corrosion of the steel coupons thereby inhibiting their corrosion in the understudied acid medium. This is corroborated by the increase in inhibition efficiency as observed in Figure 2. Equations 2 and 3 relates the proportionality of $I E$ and $\theta$ meaning as $I E$ increased with increasing L. alopecuroides concentration, the surface of the steel covered by L. alopecuroides extract also increased thereby making the steel surface inaccessible by the aggressive species in the acid medium, hence retarding its dissolution.

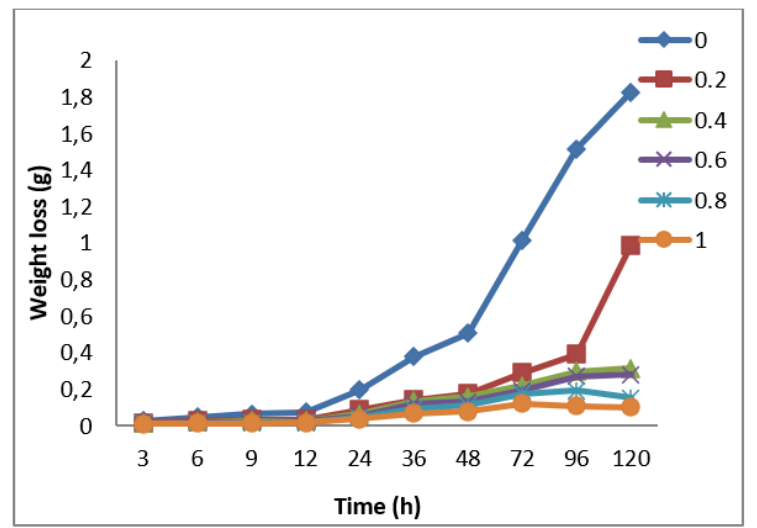

Figure 1. Variation of weight loss with time for the corrosion of mild steel in $1.0 \mathrm{M} \mathrm{HCl}$ in the absence and presence of different concentrations of L. alopecuroides at $303 \mathrm{~K}$.

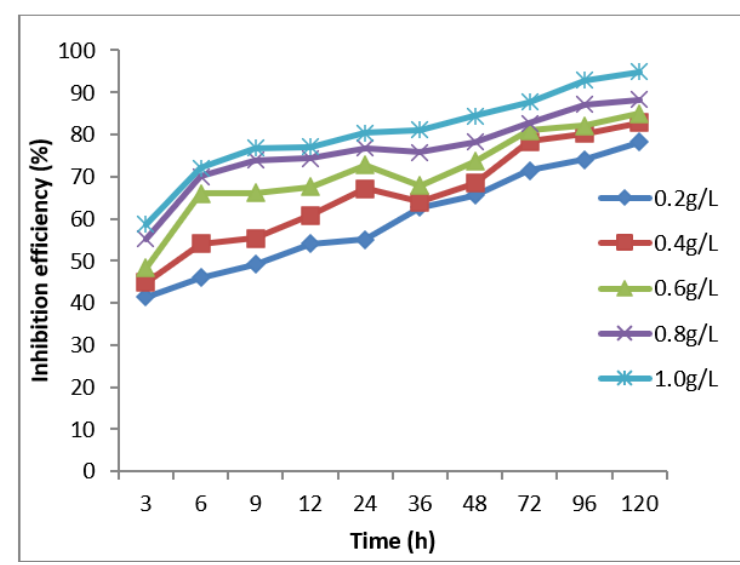

Figure 2. Variation of $I E$ with time for the corrosion of mild steel in $1.0 \mathrm{M} \mathrm{HCl}$ in the presence of various concentrations of L. alopecuroides at $303 \mathrm{~K}$.

Figure 3 shows a decrease in $I E$ with increase in temperature indicating that at higher temperatures, there was less adsorption of $L$. alopecuroides components to the surface of the metal. This condition typifies physical adsorption mechanism as corroborated by other findings $[8,20-23]$. The decrease in $I E$ with increase in temperature means that the adsorbed components of $L$. alopecuroides on the steel surface were electrostatically bond to the steel surface and at as the temperature of the system increased, there was increase in the kinetic motion of the molecules in the corrodent and subsequent agitation of the adsorbed species on the steel surface causing their desorption from it with a resulting decrease in surface coverage of the inhibitor and $I E$.

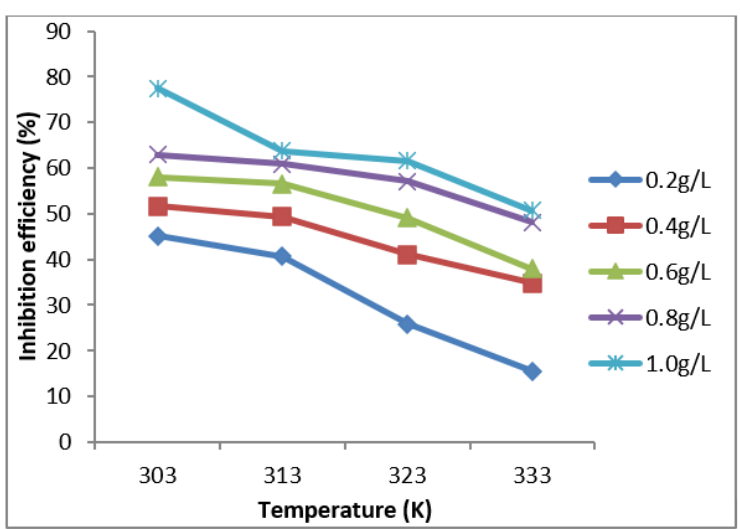

Figure 3. Variation of $I E$ with temperature for the corrosion of mild steel in $1.0 \mathrm{M} \mathrm{HCl}$ in the presence of different concentrations of L. alopecuroides at $303 \mathrm{~K}$.

\subsection{Linear polarization}

The relationship between the current and potential for the corrosion of mild steel electrode in the inhibited and uninhibited test solutions is illustrated in the Tafel plots in Figure 4. The presence of L. alopecuroides in the test solution can be observed to affect both the anodic and cathodic half reactions, moving the corrosion potential ( $\left.E_{\text {corr }}\right)$ toward a more positive value and decreasing the anodic and cathodic current densities and the corresponding corrosion current density ( $\left.i_{\text {corr }}\right)$. This means that $L$. alopecuroides is a mixed-type inhibitor in the corrosion inhibition of mild steel in the $\mathrm{HCl}$ medium $[5,7,20,21]$. The inhibition efficiency of $L$. alopecuroides extract was calculated using Equation 4 and presented on Table 1.

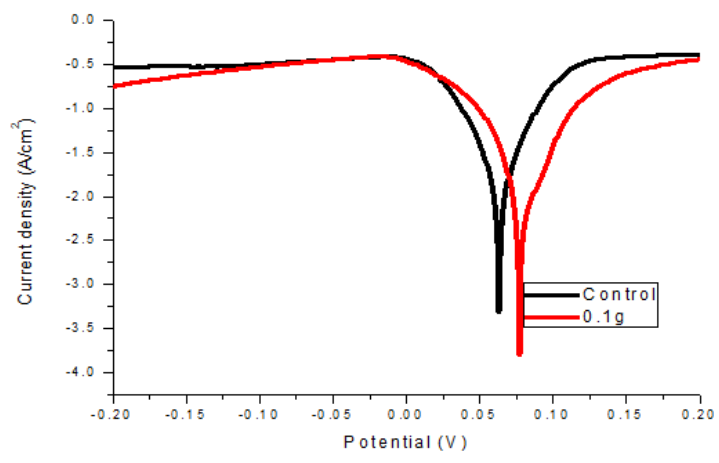

Figure 4. Tafel plots for the corrosion of mild steel in $1.0 \mathrm{M}$ $\mathrm{HCl}$ in the presence of $L$. alopecuroides.

Table 1. Linear polarization parameters for the corrosion of mild steel in $1.0 \mathrm{M} \mathrm{HCl}$ in the presence of $L$. alopecuroides.

\begin{tabular}{lcllccc}
\hline $\begin{array}{l}\text { Conc } \\
(\mathbf{g} / \mathbf{L})\end{array}$ & $\begin{array}{c}\mathbf{E}_{\text {corr }} \\
(\mathbf{V})\end{array}$ & $\begin{array}{c}\mathbf{I}_{\text {corr }} \\
\left(\mathbf{A} / \mathbf{c m}^{\mathbf{2}}\right)\end{array}$ & $\begin{array}{c}\boldsymbol{\beta a} \\
(\mathbf{V} / \mathbf{d e c})\end{array}$ & $\begin{array}{c}\boldsymbol{\beta c} \\
(\mathbf{V} / \mathbf{d e c})\end{array}$ & $\begin{array}{c}\boldsymbol{C R} \\
(\mathbf{g} / \mathbf{h})\end{array}$ & $\begin{array}{c}\boldsymbol{I E} \\
(\boldsymbol{\%})\end{array}$ \\
\hline Blank & 0.063 & 0.824 & 0.313 & 0.405 & 0.429 & - \\
$\mathbf{0 . 1}$ & 0.076 & 0.116 & 0.130 & 0.214 & 0.060 & 85.92 \\
\hline
\end{tabular}

\subsection{Temperature and kinetics}

The Arrhenius equation describes the relationship between the temperature of the system and the corrosion rate of the steel coupon [20-23]: 


$$
C R=A \exp \left(-\frac{E_{a}}{R T}\right)
$$

where $C R$ is the corrosion rate of the steel coupon in $\mathrm{g} \cdot \mathrm{cm}^{-2} \cdot \mathrm{h}^{-1}, E_{a}$ is the activation energy of the corrosion and inhibition process, $A$ is the pre-exponential factor, $T$ is the absolute temperature $(\mathrm{K})$ and $R$ is the universal gas constant.

Taking the logarithm of both sides of Equation 5 yields,

$$
-\log C R=\log A-\frac{E a}{2.303 R T}
$$

The plot of $\log C R$ vs. 1/T for the corrosion of mild steel in the absence and presence of different amounts of L. alopecuroides extract is illustrated in Figure 5a. The activation energies are presented on Table 2.
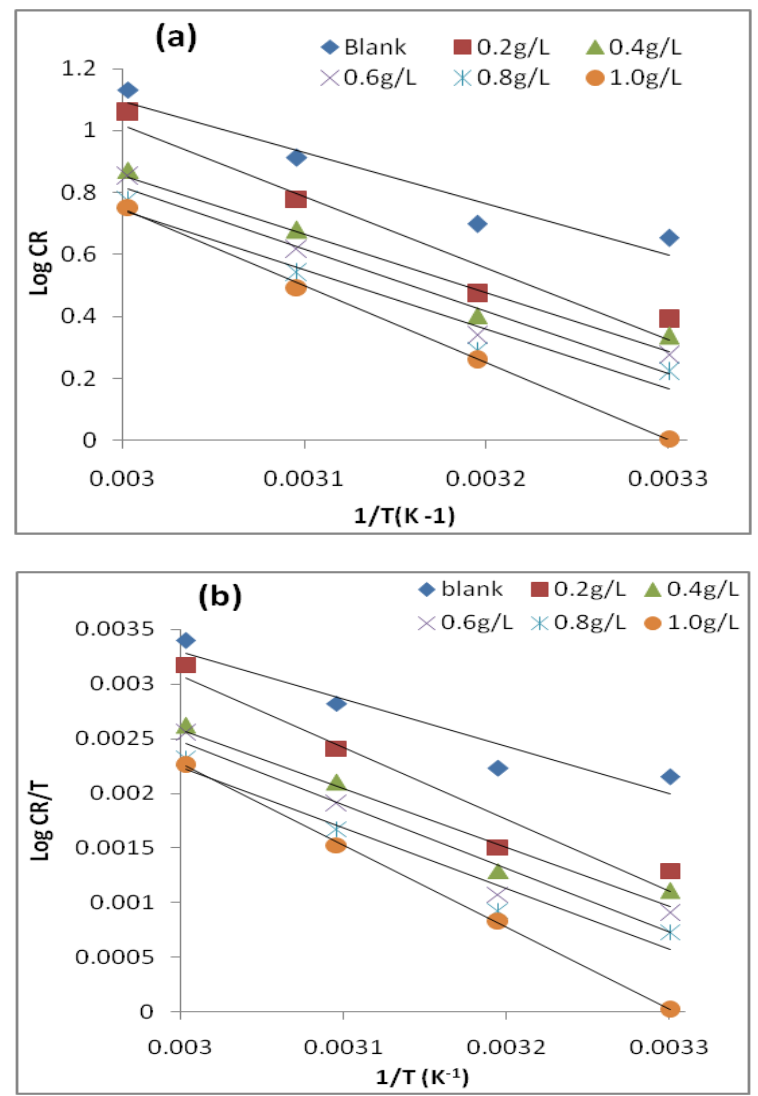

Figure 5. (a) Arrhenius and (b) Transition state plots for the corrosion of mild steel in the absence and presence of different levels of $L$. alopecuroides in $1.0 \mathrm{M} \mathrm{HCl}$.

The activation energies for the corrosion of mild steel in the absence and presence of different amounts of L. alopecuroides plant extract in the acid medium are presented on Table 2.

The value of $E_{a}$ in the uninhibited system not only increased on addition of $L$. alopecuroides extracts, but all the values of $E_{a}$ in both the inhibited and free acid systems were less than $80 \mathrm{~kJ} / \mathrm{mol}$ signifying a physisorptive kind of adsorption mechanism as earlier suggested.

The other activation parameters $\left(\Delta S^{*}\right.$ and $\left.\Delta H^{*}\right)$ for the adsorption of $L$. alopecuroides extracts on the steel coupon were calculated using Equation 7 [6, 20-23],

$$
\log \left(\frac{C R}{T}\right)=\left[\log \left(\frac{R}{N h}\right)+\frac{\Delta S^{*}}{2.303 R}\right]-\frac{\Delta H^{*}}{2.303 R T}
$$

where $\Delta S^{*}$ is change in entropy of activation, $\Delta H^{*}$ is the change in enthalpy of activation, $C R$ is the corrosion rate at absolute temperature $T, h$ is the Planck's constant, $N$ is the Avogadro's constant, $(6.02 \mathrm{E}-23)$ and $R$ is the universal gas constant.

A plot of $\log C R / T$ versus $1 / T$ is a straight-line graph with a slope of $\left(-\frac{\Delta H *}{2.303 R}\right)$ and an intercept of $\left[\log \left(\frac{R}{n h}\right)+\right.$ $\left.\frac{\Delta S *}{2.303 R}\right]$ (Figure 5b) from which the values of $\Delta H^{*}$ and $\Delta S^{*}$ were calculated respectively and presented on Table 2 [21-23].

Table 2. Values of $E_{a}, \Delta H^{*}$ and $\Delta S^{*}$ for the corrosion of mild steel in $1.0 \mathrm{M} \mathrm{HCl}$ in the absence and presence of different concentrations of $L$. alopecuroides extract.

\begin{tabular}{lccc}
\hline \multicolumn{1}{c}{ Test } & $\begin{array}{c}\boldsymbol{E}_{\mathbf{a}} \\
(\mathbf{k J} / \mathbf{m o l})\end{array}$ & $\begin{array}{c}\Delta \boldsymbol{H}^{*} \\
(\mathbf{k J} / \mathbf{m o l})\end{array}$ & $\begin{array}{c}\Delta \boldsymbol{S}^{*} \\
(\mathbf{k J} / \mathbf{m o l})\end{array}$ \\
\hline Blank & 30.872 & 82.92 & -197.28 \\
$\mathbf{0 . 2} \mathbf{~ g / L}$ & 42.969 & 126.06 & -197.16 \\
$\mathbf{0 . 4} \mathbf{~ g / L}$ & 34.495 & 102.65 & -197.24 \\
$\mathbf{0 . 6} \mathbf{~ g / L}$ & 37.105 & 110.92 & -197.22 \\
$\mathbf{0 . 8} \mathbf{~ g / L}$ & 35.544 & 106.01 & -197.24 \\
$\mathbf{1 . 0} \mathbf{g} / \mathbf{L}$ & 48.047 & 143.35 & -197.12 \\
\hline
\end{tabular}

The negative entropies of activation suggest the association mechanism of the corrosion process whereby a decrease in disorder takes place ongoing from the reactants to the activated complex as reported in other studies [12, 22, 23].

\subsection{Adsorption studies}

The adsorption properties of $L$. alopecuroides extract were analyzed by fitting the obtained data for surface coverages at $303,313,323$, and $333 \mathrm{~K}$ into different adsorption isotherm models. The Temkin adsorption isotherm gave the best fit. Equation 8 is the mathematical (linear form) form Temkin adsorption isotherm,

$$
-2 \propto \theta=2.303\left(\log K_{a d s}+\log C\right)
$$

where $C$ is the concentration of $L$. alopecuroides in the bulk electrolyte, $\theta$ is the degree of surface coverage of L. alopecuroides, $K_{a d s}$ is the adsorption equilibrium constant and $\propto$ is the molecular interaction parameter.

By plotting $\log C$ against $\theta$ at the understudied temperatures as shown in Figure 6 , the $R^{2}$ values show that the adsorption pattern fits more perfectly into this model as the values were close to unity.

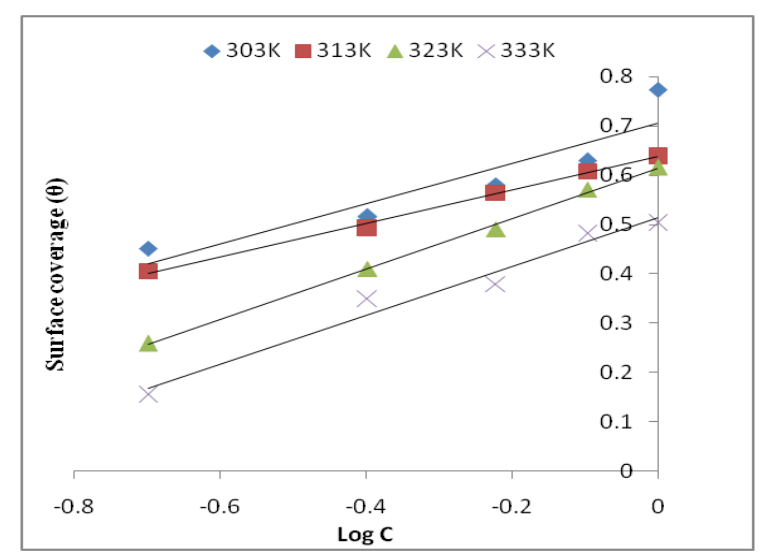

Figure 6. A plot of Temkin adsorption isotherm for the adsorption of $L$. alopecuroides extraction the surface of mid steel in $1.0 \mathrm{M} \mathrm{HCl}$ 
The free energy of adsorption, $\Delta G^{o}$ ads, can be calculated using Equation 9:

$$
\Delta G^{o}{ }_{a d s}=-2.303 R T \log \left(55.5 K_{a d s}\right)
$$

Values of adsorption parameters deduced from the plots are presented on Table 3.

Table 3. Temkin isotherm parameters for the adsorption of $L$. alopecuroides extract on the surface of mild steel in $1.0 \mathrm{M}$ $\mathrm{HCl}$ at different temperatures.

\begin{tabular}{lccc}
\hline Temperature & $\boldsymbol{K}_{\text {ads }}$ & $\begin{array}{c}\Delta \boldsymbol{G}_{\text {ads }}^{\mathbf{~}} \\
(\mathbf{k J} \mathbf{J} \mathbf{m o l})\end{array}$ & $\boldsymbol{R}^{\mathbf{2}}$ \\
\hline $\mathbf{3 0 3} \mathbf{~ K}$ & 2.026 & -11.897 & 0.8508 \\
$\mathbf{3 1 3} \mathbf{~ K}$ & 1.892 & -11.724 & 0.9958 \\
$\mathbf{3 2 3 ~ K}$ & 1.849 & -11.666 & 0.9982 \\
$\mathbf{3 3 3 ~ K}$ & 1.671 & -11.411 & 0.9729 \\
\hline
\end{tabular}

The values of $K_{a d s}$ in Table 3 are low which is indicative of interactions that are not strong between the plant extract and the surface of the steel coupon. Higher values of $K_{a d s}$ have been reported to illustrate greater adsorption of the adsorbate (plant extract) on the adsorbent (steel surface), better inhibition efficiency and vice versa [8, 25]. This supports physisorptive mechanism of adsorption of L. alopecuroides extract on the steel surface $[8,25]$.

The negative values of $\Delta G^{o}$ ads obtained on Table 3 infer that the adsorption of $L$. alopecuroides extract on the steel surface was spontaneous [21-24]. Values of $\Delta G_{\text {ads }}^{o}<-40 \mathrm{~kJ} / \mathrm{mol}$ is linked with electrostatic interactions between inhibitor molecules and the charged metal/alloy surface (physisorption) [21-24]. The values of $\Delta G^{o}$ ads obtained in this study were $<-20$ $\mathrm{kJ} / \mathrm{mol}$ (Table 3 ) confirming physical adsorption of the L. alopecuroides extract on the steel surface.

\section{Conclusion}

This study has shown that L. alopecuroides contains alkaloids, saponins, steroids, terpenes and glycosides, and served as an excellent inhibitor for the corrosion of mild steel in $1.0 \mathrm{M} \mathrm{HCl}$. Inhibition efficiency of the plant extract increased with increase in concentration of the extract but decreased with increase in temperature. Tafels plots revealed L. alopecuroides inhibited both the dissolution of the steel at the anode and the hydrogen evolution reaction at the cathode making it a mixed inhibitor. Evaluated activation energy, $E_{\mathrm{a}}$ and $\Delta G_{\text {ads }}^{\mathrm{o}}$ values reveal the corrosion inhibition process to be physisorptive and spontaneous while the Temkin isotherm model described the adsorption mechanism of L. alopecuroides to the steel surface.

\section{Conflict of interest}

The authors do not declare any conflict of interest.

\section{References}

[1]. Z. Ahmad, Principles of corrosion engineering and corrosion control, Butterworth-Heinemann, London, UK (2006).

[2]. P. R. Roberge, Handbook of corrosion engineering, New York McGraw-Hill, 2000. https://www.cntq.gob.ve/cdb/documentos/quimica /197.pdf.
[3]. H. Momoh-Yahaya, N.O. Eddy, J.F. Iyun, C.E. Gimba, E.E. Oguzie, Inhibitive and adsorptive behaviour of guanine on corrosion of mild steel in $0.1 \mathrm{M} \mathrm{HCl}$ and $\mathrm{H}_{2} \mathrm{SO}_{4}$, International Journal of Modern Chemistry 2 (2012) 127-142.

[4]. H.F. Chahul, G.I. Ndukwe, S.T. Abawua, Corrosion inhibition studies of mild steel with stem bark extract of Maranthes Polyandra (benth.) prance, Journal of Chemical Society of Nigeria 42 (2017) 55-61.

[5]. H. Momoh-Yahaya, N.O. Eddy, J.F. Iyun, C.E. Gimba, E.E. Oguzie, Experimental investigation of the inhibiting action of adenine on the corrosion of mild steel in acidic environments, Journal of Materials Science Research 2 (2013) 59-74.

[6]. H. Momoh-Yahaya, N.O. Eddy, E.E. Oguzie, Inhibitive, adsorptive and thermodynamic study of hypoxanthine against the corrosion of aluminium and mild steel in sulphuric acid, Journal of Materials and Environmental Science 5 (2014) 237-244.

[7]. A. Peter, I.B. Obot, S.K. Sharma, Use of natural gums as green corrosion inhibitors: an overview, International Journal of Industrial Chemistry 6 (2015) 153-164.

[8]. H. Ashassi-sorkhabi, B. Shaabani, B. Aligholipour, D. Seifzadeh, The effect of some Schiff bases on the corrosion of aluminium in $\mathrm{HCl}$ solution, Applied Surface Science 252 (2006) 4039-4047.

[9]. B. Lin, J. Tang, Y. Wang, H. Wang, Y. Zuo, Study on synergistic corrosion inhibition effect between calcium lignosulfonate (CLS) and inorganic inhibitors on Q235 carbon steel in alkaline environment with $\mathrm{Cl}^{-}$, Molecules 25 (2020) 4200. DOI:10.3390/molecules25184200

[10]. K. Ramya, R. Mohan, K.K. Anupama, A. Joseph, Electrochemical and theoretical studies on the synergistic interaction and corrosion inhibition of alkyl benzimidazoles and thiosemicarbazide pair on mild steel in hydrochloric acid, Material Chemical Physics 149-150 (2015) 632-647.

[11]. M.U. Akpuaka, S.N. Ezem, Preliminary phytochemical screening of some Nigeria dermatological plants, Journal of Basic Physical Research 2 (2011) 1-5.

[12]. H.F. Chahul, D.T. Orhemba, T.A. Gbadamosi, Influence of Cissus populnea stem extract on kinetics and thermodynamics of mild steel corrosion in acidic medium, Ovidius University Annals of Chemistry 30 (2019) 14-20. DOI: 10.2478/auoc-2019-0003

[13]. H.F. Chahul, A.M. Ayuba, S. Nyior, Adsorptive, kinetic, thermodynamic and inhibitive properties of Cissus populnea stem extraction the corrosion of aluminum in $\mathrm{HCl}$, ChemSearch Journal 6 (2015) 20-30.

[14]. G.A. Ijuo, H.F. Chahul, I.S. Eneji, Kinetic and thermodynamic studies of corrosion inhibition of mild steel using Bridelia ferruginea extract in an acidic environment, Journal of Advanced Electrochemistry 2 (2016) 107-112. 
[15]. P.O. Ameh, Electrochemical and computational study of gum exudates from Canarium schweinfurthii as green corrosion inhibitor for mild steel in $\mathrm{HCl}$ solution, Journal of Taibah University of Science 12 (2018) 783-795.

[16]. P.B. Raja, M. Ismail, S. Ghoreishiamiri, J. Mirza, M.C. Ismail, S. Kakooei, A.A. Rahim, Reviews on corrosion inhibitors: A short view, Chemical Engineering Communications 203 (2016) 11451156.

[17]. G.I. Ndukwe, S.Y. Garba, E.A. Adelakun, Activity-guided isolation and antimicrobial assay of a flavonol from Mitracarpus verticillatus (Schumach. \&Thonn.) Vatke, IOSR Journal of Applied Chemistry 9 (2016) 118-131.

[18]. H.F. Chahul, G.I. Ndukwe, D.O. Ogwu, A thermometric study on the kinetics of the acid dissolution of aluminium in the presence of Napoleonaea imperialis seeds extract and iodide ions, Ovidius University Annals of Chemistry 29 (2018) 103-109. DOI: 10.2478/auoc-2018-0015

[19]. H.F. Chahul, G.I. Ndukwe, A.A. Ladan, Adsorption behaviour and corrosion inhibition effect of $N$. imperialis p. beauv (Lecythidaceae) seed extract on mild steel in $1.0 \mathrm{M} \mathrm{HCl}$, ChemSearch Journal 10 (2019) 25-32.
[20]. H.F. Chahul, E. Maji, R. Shaato, Kinetics and thermodynamics of the corrosion of mild steel in the presence of Euphobia tirucalli gums, European Chemical Bulletin 7 (2018) 337-344.

[21]. A.K. Singh, M.A. Quraishi, Piroxicam: A novel corrosion inhibitor for mild steel corrosion in $\mathrm{HCl}$ acid solution, Journal of Materials and Environmental Science 1 (2010) 101-110.

[22]. S. K. Shukla, M.A. Quraishi, Ceftriaxone: A novel corrosion inhibitor for mild steel in hydrochloric acid, Journal of Applied Electrochemistry39 (2009) 1517-1523.

[23]. M.H. Refat, A.Z. Ishaq, Kinetics of corrosion inhibition of aluminium in acidic media by watersoluble natural polymeric pectates as anionic polyelectrolyte inhibitors, Materials 6 (2013) 2436-2451.

[24]. I.B. Obot, N.O. Obi-Egbedi, Fluconazole as an inhibitor for aluminium corrosion in $0.1 \mathrm{M} \mathrm{HCl}$, Colloids and Surfaces A: Physicochemical Engineering Aspects 330 (2008) 207-212.

Received: 28.08.2020

Received in revised form: 29.01.2021

Accepted: 30.01.2021 